\title{
THE EFFECTS OF NANOPARTICLES ON SPORULATION AND ACTIVE
}

\author{
POPULATION OF TALAROMYCES FLAVUS \\ LALEH NARAGHI, MARYAM NEGAHBAN, ASGHAR HEYDARI \\ MOHAMMAD RAZAVI \&HOMAYOUN AFSHARI-AZAD
}

Iranian Research Institute of Plant Protection, Agricultural Research,

Education and Extension Organization (AREEO), Tehran, Iran

\begin{abstract}
The importance of the Talaromyces flavus antagonistic fungus has been understood for inhibiting the growth of some of the important plant pathogenic agents such as Rhizoctonia solani, Verticillium dahliae and Fusarium oxysporum. Additionally, based on the results of previous research, preparation of the mentioned fungal bioformulation was possible with substrates in the form of various plant residues such as rice bran and wheat straw. The application of this bioformulation in the greenhouse and the field, in addition to reducing the incidence of seedling damping-off, Verticillium wilt and Fusarium wilt diseases in cotton, sugar beet, potato, tomato and greenhouse cucumber, while increases their yields. According to the obtained results, the commercialization of the bioformulation of this fungus has particular importance. Since the marketing is considered to be an important factor in the continuation of commercialization, considering the type of bioformulation with ease of use can greatly affect the attraction of relevant consumers and a successful marketing. Therefore, due to the recent advances in the application of nanotechnology in various sciences, it seems necessary in the further research to investigate different nanoformulations from the biological agent with an emphasis on the ease of use, preparation and their efficacy in biological control of plant diseases. In this study, nanoformulations were prepared in three types: nanocapsule (F1 and F3), nanoemulsion (F2), and nanopowder (F4). Three and six months after production, laboratory experiments on nanoformulations and the formulation based on previous technical knowledge (rice bran and T. flavus) on sporulation and active population of the antagonistic fungus were carried out in a completely randomized design. The results showed that there was a significant increase in sporulation and active population in nanopowder compared to other formulations.
\end{abstract}

KEYWORDS: Active Population, Nanoparticle, Talaromyces Flavus \& Sporulation

Received: Feb 20, 2018; Accepted: Mar 10, 2018; Published: Mar 31, 2018; Paper Id.: IJBTRAPR20184

\section{INTRODUCTION}

In the studies conducted in Iran, appropriate results of Talaromyces flavus antagonistic fungus on controlling some of the most important plants pathogenic agents such as Verticillium dahliae, Verticillium albo-atrium, Fusarium oxysporum and Rhizoctonia solani in several crops including cotton, sugar beet, potato, tomato and greenhouse cucumber have been proven (Ardekani et al., 2009; Shahraki et al., 2009; Heydari and Pessarakli, 2010; Kakvan et al., 2013; mansoori et al., 2013). Also, the application of this fungus in the fields, reduced the incidence of disease and increased yield in the above products; in cotton plant, $50 \%$ reduction in the percentage of verticillin wilt disease, $37 \%$ reduction in seedling mortality and 30\% increase in yield; in potato plants, $40 \%$ decrease in disease percentage and $17 \%$ increase in yield (Naraghi et al., 2014b); of sugar beet, 93\% Increasing the number of healthy seedlings and 50\% increase in yield (Naraghi et al., 2014a); in tomato plants, 27\% reduction in disease severity and 23\% increase in yields (Farhang Niya et al., 2015) and in the greenhouse cucumber, 30\% reduction in the severity of the disease and $7 \%$ 
increase in yield. Since mass production and marketing of biological agents, the marketing issue and attraction of the relevant consumers, (Husen et al., 2006; Alimi et al., 2009; Kaewchai et al., 2009; Pereira et al., 2009); at present, the commercialization of the biological agent, T. flavus and the importance of the production of various formulations, including nanoformulations, seem essential.

Recent developments in nanotechnology have significantly increased in various fields of pharmaceutical chemistry, medicine, and chemical pesticides. The pest resistance phenomenon to pesticides necessitates conducting researches and development in the field of nanoparticles; therefore, the introduction of nanosciences to researchers will boost research and development in this relatively new field. Considering the environmental problems and costs associated with the consumption of large amounts of pesticides, as well as the problems caused by the resistance of pests to these pesticides, investigations, and development about nanoformulations can be considered as a necessity.

The use of biodegradable polymers in producing nanoemulsions and highperformance nanoparticles made of natural and biodegradable materials can be an effective step in this field. In order to increase efficiency and reduce environmental hazards, encapsulated formulation is the best option (Maji et al., 2014). Therefore, the production of bioformulation in the form of nanoscale and microscale provides a controlled ability, increased strength and stability, and protects the active ingredient in adverse environmental conditions such as light and moisture. Additionally, the use of nano-encapsulated formulations can help reduce pest and cost-effective dosage, and protect the environment and reduce its environmental hazards, as well as better product exports (Martin et al., 2010).

Nanoparticles have a larger surface to volume ratio than microparticles, which increases their activity level and control their release. Also, the other advantage of nanoscale particles is that these compounds do not stimulate the human and animal body and rapidly excludes the body (Guan et al., 2008).

Nanocapsules technology that contains nano-sized nanoscale fungicides or pesticides, is one of the methods for the production of formulations for pest control, which eliminates more easily and quickly pest infections (Guan et al., 2008). An emulsion is a heterogeneous system composed of two non-intermolecular liquids, one of which is dispersed in droplets in another. Emulsions with a droplet size of nano-scale and a typical size ranged from 20 to $200 \mathrm{~nm}$ (Ostertag et al., 2012). The unique structure and properties of nano-emulsions have produced many advantages in many industries compared with conventional emulsions. The applications of nanoemulsion systems in industries can be observed in their role in encapsulating and controlling the release of superoxide compounds, such as essential oils, vitamins, etc. (Hofman and Kan, 2014).

Recently, production of nanoparticles that are more biodegradable and have high efficiency are highly considered. Therefore, the use of biodegradable polymers in the production of high-performance nanoemulsions and nanocapsules made of natural and biodegradable materials such as essential oil of medicinal plants can be an effective step in this field. The use of nanopesticides, and also their production, application and environmental considerations indicate that conducting researches and development can be effective in reducing pest resistance phenomena to pesticides. The nano formulations used by microorganisms, such as bacteria and fungi, are used in the biological struggle against insects and facilitate the entry of agents to insects (Salukhe et al., 2011). The formulation of the primitive nano-primer causes good preservation of the formulation in the dark and be more stable (Wan et al., 2010). 
The formulation of nanoextraction of plants from resistant pests to pesticides was more than five times more potent than pesticides (Rajakumara and Rahuman, 2011). The formulation of nano-permeate by evaporation of oil solvent in water could have a better effect on controlling the larva of the mosquito coils (Anjali et al., 2010). The mortality ,property of Bacillus thuringiensis has been investigated using nanoparticles of chitosan polymer on Anopheles mosquito larvae (Zhang et al., 2015). In addition, the use of dextrose and gelatin bioaccumulation containing Beauveria, Metharhisium and Paecilomyceswere prepared against Hypothenemushampei (Niranjana et al., 2004).

However, Beauveriabassiana was used for the formulations containing silver nanoparticles were used as larvae (Prabakaran et al., 2016). In a study on the disinfection effects of barley and sunflower seeds with silver nanoparticles containing fungicides on mycorrhizal symbiosis, it was found that, in comparison with conventional fungicide, in seed treatment with bread wrappers, a significant increase in the absorption of mineral elements by the root and consequently a significant increase in vegetative traits was observed (Abbasian et al., 2010; Faghani and Rajaee, 1393). Covering materials for encapsulation include gum, starch, gelatin and polymers. Recently, chitosans and phospholipids are also used. According to recent research, the use of nonadaptation techniques and their components in storage pest management can play an important role in increasing their efficiency and durability (Prasad et al., 2014).

A large number of insecticidal plant compounds are highly evaporated and susceptible to decomposition. The loading of plant compounds into nanoparticles controlled release delaying decomposition and evaporation. There are limited articles about the effect of nano emulsion insecticides and nanocapsules loaded with pesticide-based compounds against insect pests (Margulis-Goshen and Magdassi, 2013).

There are several methods for producing nanoparticles or nanocapsules among which, the polymerization method, which is one of the fastest methods, is continuously mixed with continuous organic phase (Kirthi et al., 2011). It is also a method of co-precipitation and ion gelling using biodegradable water-like polymers such as chitosan, gelatin, sodium alginate, which is in fact a mixture of two-phase aqueous that is placed in a polymeric phase such as chitosan and sodium alginate, and in this method, positive charge of the polymer is neutralized with a negative charge of crosses links, such as sodium triphosphate or calcium chloride, and form capsules (Ebrahimnejad et al., 2011).

So far, there have been two reports in the field of medicine and agriculture for the preparation of the fungus nicotine (Penicillium) (Priyadarshini et al. 2014; Khan and Jameel, 2016). In the field of medicine, the fungus of Penicillium fellutanum has been used for the preparation of pesticides against the Candida albicans. In the field of agriculture, for the preparation of nicotine against some plant diseases, the extract of the fungus Talaromyces flavus (Penicillium dangeardii) was used.

In the last 20 years, there have been significant reports on the preparation of formulations containing antagonistic fungi using solid and liquid fermentation and their optimization in various stages of production (Pascual et al., 1999; Budge and Whipps, 2001; Schuster and Schmoll, 2010; Caramez et al., 2012; Kakvan et al., 2013; Sargin et al., 2013). For example, Pascual et al. (1999), succeeded in producing solid bioformulation from Epicoccum nigrum on wheat, and after analyzing alcoholic solutions containing glycerol, mannitol and arabitol on sporulation of this fungus, the most significant increase was observed The sporulation was reported by glycerol. Also, Sargin et al. (2013) tried to increase the efficiency of the bioformulation containing Trichoderma harzianum EGE-K38, compared with the different methods of drying this bioformulation. Research results have shown that the use of compounds containing minerals such as manganese, iron, zinc, 
and phosphorus in the production of biological formulations containing antagonistic fungi has increased their stability (Vasane and Kothari, 2008; Lee and Lee, 2009).

So far, overseas bioformulations such as Ketomium containing Chaetomium globosum and $\mathrm{Ch}$. Cupreum; Promote containing T. harzianum and T. Virus; Soil Gard contains Gliocladium virens; Trichodex containing T. harzianum, Pisolithus tinctonus and Glomus intraradices; Trichodermin containing T. harzianum and Protus WG containing Talaromyces flavus has been commercially registered (Merwel et al., 1974; Koch, 1999; Kaewchai et al., 2009).

\section{MATERIALS AND METHODS}

\section{Preparation of Nanocapsules Containing Talaromyces Flavus}

The production of nanocapsules is a combination of the polymerization and networking process, which was applied by making changes consistent with the conditions of the growth of the biological fungus (changes in the amount or type of polymer, surfactants, and oils, fatty acid and the amount of agitator, temperature). In the polymerization process, the organic phase containing vegetable oil with a mixture of biological mushrooms added in a water phase consisting of hydrophilic polymer monomers such as a mixture of one of two polymers of formaldehyde polymer, or originate, starch and chitosan. Subsequently, in the sum of two phases, the Karsan linkers such as calcium chloride, as well as surfactants and the accompanying materials, and fatty acid oils were added, and the homogenization at a temperature of $35^{\circ} \mathrm{C}$ was homogenized with a range of 5,000 to 10,000 rpm. Finally, polymer particles formed in the form of a capsule around the particles of the biological fungus.

\section{Preparation of Nanoemulsion Containing Talaromyces Flavus}

The self-assemblage pattern was used to produce nanoemulsion containing T. flavus. The final formulation of a nanoemulsion was formulated in a biocompatible formulation of plant oilnano-particles. The compositions of this formulation were: the active ingredient of the biological fungus and vegetable oil, such as hydrogenated castor, tungsten surfactant, carboxymethylcellulose viscous material, coconut moisturizer, ethanol amide fatty acid, a stabilizing agents such as poly-vinyl -alcohol and linker such as calcium chloride and biocompatible polymers such as ethylene glycol and starch. First, a uniform solution of biocompatible polymers was prepared, then surfactants such as twin and the accompanying materials were added to the solution and a completely homogeneous mixture of polymer and solvent was prepared with a homogenized with 2000 to $12000 \mathrm{rpm}$ at $25^{\circ} \mathrm{C}$. Then, suspensions containing spores of biological fungi along with fatty acids of castor oil and coconut oil were added as drop drops. In the next step, a total of two phases, crosslinker (calcium chloride) was added to form the nanoparticles around the spores of the biological fungus. Finally, the nanoparticles were surrounded by spores of the biological fungus.

\section{Preparation of Nanopowder Containing Thalaromyces Flavus}

In powdered nanoformulation, a suspension containing biological fungal spores in the aqueous phase, including maltodextrin, xanthan gum (Xanthan Gum), fatty acid, ethanol amide and oleic acid, and then placing in a homogenized with 2000 to $12000 \mathrm{rpm}$ at $25^{\circ} \mathrm{C}$ was completely powdered.

\section{Preparation of T. Flavus Bioformulation Based on Previous Technical Knowledge}

To prepare solid formulation, an effective isolate of T. flavus in the fungi collection of research laboratory ofuseful microorganisms and modified by Naraghi et al. (2010a) was used. So that some rice bran was washed in water 
$\left(30-35^{\circ} \mathrm{C}\right)$ for 24 hours, then spread out and dried on large filter paper. In the next step, $250 \mathrm{~g}$ of rice bran was sterilized in autofocus cellophane bags (one and a half atmospheres, $121^{\circ} \mathrm{C}$ for 20 minutes). In the next step, $40 \mathrm{ml}$ sterilized distilled water was added to the suspension, and six half-centimeter pieces of the 10-day culture medium of T. flavus isolate were poured into cellophane bags. Then, one of the stabilizing compounds, such as dicycloserine or sodium nitrate, was added based on the amount of supplementation of the supplements to the culture media $(10 \mathrm{ml}$ of complement solution at $20 \mathrm{~g} / \mathrm{l}$ for $250 \mathrm{~g}$ of each substrate) (Engelelkes et al., 1997). For the growth of T. flavus isolate, the cellophane sachet was placed in the $30^{\circ} \mathrm{C}$ for one month and a half to two months, and during this period, if the contents were dried, $20 \mathrm{ml}$ of distilled water was added again to create moisture. After this time, the contents of the cellophane bag expanded to dry on filter paper and used as bioformulation based on previous technical knowledge.

\section{Comparison of Production Process of Ascospores in Various Formulations of T. Flavus (New Nanoformulations and Previous Bioformulation)}

The production process of Ascospore in various formulations of T. flavus for one and a half years will be compared. This comparison began three months after the production, and will continue for up to fifteen months at intervals of three months. For this purpose, according to Naraghi et al. (2006), a dilution of one thousandth was prepared from each formulation prepared by $T$. flavus, and one tenth of this dilution was speared on the hemocytometer slider and spores were counted. One gram of each formulation was then delivered in a volume of $10 \mathrm{ml}$ and, after preparing a dilution of one thousandth suspensions, the number of spores per milliliter of the suspension prepared by hemocytometer was calculated. This study was conducted in a completely randomized design with five treatments (four new nanoformulations and one bioformulation based on previous technical knowledge) with three replications. Data analysis and comparison of mean number of spores per gram of formulation with Duncan's multiple range test was performed by MS TAT C softwares. In this stage of the study, the sporulation process in different formulations of $\mathrm{T}$. flavus have been carried out up to six months after the formulation.

\section{Comparison of Active Population (Sustainability) in Different Formulations of T. Flavus (New Nanomorphisms and Previous Bioformation)}

Investigation of the active population in different formulations of $\mathrm{T}$. flavus for one and a half years will be done. This comparison began three months after the production, and continues for up to fifteen months at intervals of three months. For this purpose, each of the formulation prepared by T. flavus, a suspension of 10 and 100 spores per milliliter, and one milliliter of each of the concentrations were placed on medium patches Potato Dextrose Agar (PDA) culture was cultivated. After observation of spores in Petri's dishes of both concentrations, the number of colonies obtained from spore growth in a concentration that was done with greater ease was counted.

After calculating the percentage of active spores, the active population in each formulation was estimated by the product of the percentage of active spores in the number of spores per gram of formulation obtained from the previous stage. This study was conducted in a completely randomized design with five treatments (four new nanoformulations and one bioformulation based on previous technical knowledge) with three replications. Data analysis and comparison of the mean number of spores per gram of formulation with Duncan's multiple range test was performed by MS TAT C software. Until this stage of the study, the active population of $T$. flavus in different formulations were performed up to six months after the formulation was made. 


\section{RESULT AND DISCUSSIONS}

\section{Comparison of Production Process of Ascospores in Various Formulations of} T. Flavus (Nanoformulations and Previous Bioformulation)

In the first and second three months after the preparation, the sporulation of the various formulations was studied (Figures 1 and 2) and the calculation of spores in one gram of each formulation showed that the mentioned amount was unchanged from the first three months for the second three months in nanocapsules and nanoemulsion, while in other formulations, especially in nanopowder, it increased (Table 1). The sporulation study in different formulations in the first and second three months after preparation was significant at the $1 \%$ probability level.

In the first three months after the preparation, the comparison of the means of the spore numbers per gram of each formulation showed that the formulations were located in four statistical groups, and the most effective ones were nanocapsule and nanoemulsion in term of sporulation (Table 1). However, in the second three months after the preparation, the comparison of the means of the spore numbers per gram of each formulation showed that the formulations were located in two statistical groups and the most effective ones were nanocapsule 1, nanoemulsion and nanopowder in term of sporulation (Table 1).
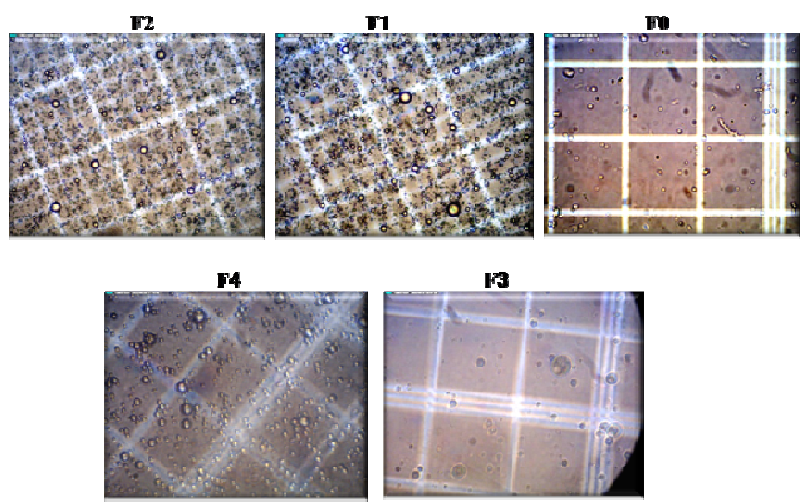

Figure 1: Sporulation Study of Various Formulations in the First Three Months after Preparation F0 (Previous Bioformulation), F1 (Nanocapsule 1), F2 (Nanoemulsion) F3 (Nanocapsule 2) and F4 (Nanopowder)
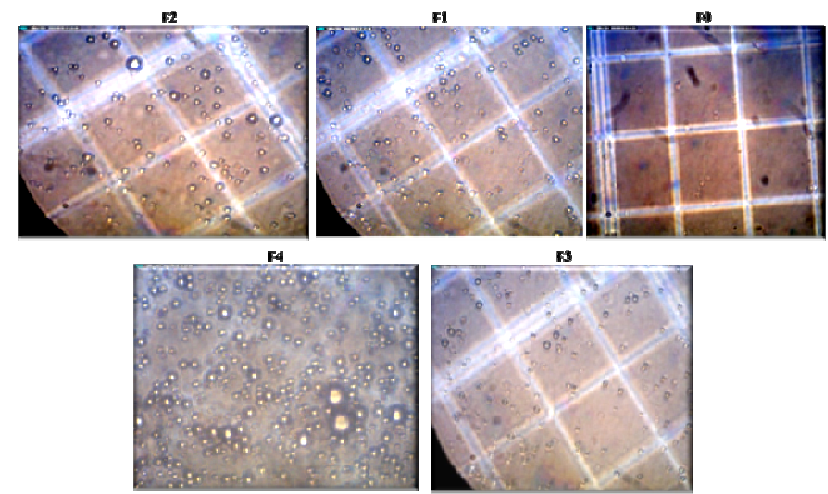

Figure 2: Sporulation Study of Various Formulations in the Second Three Months after Preparation Fo (Previous Bioformulation), F1 (Nanocapsule 1), F2 (Nanoemulsion), F3 (Nanocapsule 2) and F4 (Nanopowder) 
Table 1: Comparison of the Means of the Spore Numbers Per Each Gram among Different Talaromyces Flavus (Formulations Based on Nanotechnology and Rice Bran Formulation Based on Previous Technical Knowledge) in Logarithmic Basis

\begin{tabular}{|c|c|c|c|c|}
\hline \multirow[b]{3}{*}{ Formulation } & \multicolumn{4}{|c|}{ Mean Spore Numbers /Gram } \\
\hline & \multicolumn{2}{|c|}{ First Three Months } & \multicolumn{2}{|c|}{ Second Three Months } \\
\hline & $\begin{array}{c}\text { Spore Numbers } \\
\text { Per Gram In } \\
\text { Logarithmic Basis }\end{array}$ & $\begin{array}{c}\text { Spore } \\
\text { Numbers } \\
\text { Per Gram } \\
\left(\times \mathbf{1 0}^{\mathbf{9}}\right) \\
\end{array}$ & $\begin{array}{c}\text { Spore Numbers } \\
\text { Per Gram In } \\
\text { Logarithmic } \\
\text { Basis } \\
\end{array}$ & $\begin{array}{c}\text { Spore } \\
\text { Numbers Per } \\
\text { Gram }\left(\times 10^{9}\right)\end{array}$ \\
\hline $\begin{array}{l}\text { F0(Previous } \\
\text { Bioformulation) }\end{array}$ & $9.17 b^{*}$ & 1.50 & $9.25 \mathrm{c}^{*}$ & 1.80 \\
\hline F1 (Nanocapsule 1) & $10.00 \mathrm{a}$ & 10.00 & $10.00 \mathrm{a}$ & 10.00 \\
\hline F2 (Nanoemulsion) & $10.00 \mathrm{a}$ & 10.00 & $10.00 \mathrm{a}$ & 10.00 \\
\hline F3 (Nanocapsule 2) & $9.00 \mathrm{c}$ & 1.00 & $9.47 \mathrm{bc}$ & 3.00 \\
\hline F4 (Nanopowder) & $8.00 \mathrm{~d}$ & 0.1 & $9.6 \mathrm{ab}$ & 5.00 \\
\hline
\end{tabular}

* There is no statistically significant difference among the means with the same statistical letters in the $1 \%$ probability level.

\section{Comparison of Active Population (Sustainability) in Different Formulations of Talaromyces Flavus (Nanoformulatios and Previous Bioformation)}

In the first and second three months after preparation, the percent of grown spores were evaluated in the different T. flavus formulations (Figures 3 and 4) and calculating the active population in one gram of each formulation showed that the active population increased from the first three months for the second three months in different formulations (Table 2). Stability test was significant in different formulation in the first and second three months after preparation at $1 \%$ probability level.

In the first three months after preparation, the comparison of the active population per gram of each formulation showed that formulations were located in three statistical groups, and the most effective ones were former bioformulation, nanocapsule 1 and the nanocapsule 2 in term of the active population (Table 2). However, in the second three months after the preparation, the comparison of the active population per gram of each formulation showed that the formulations were located in four statistical groups and the most effective one was nanopowder in term of the active population (Table 2). 

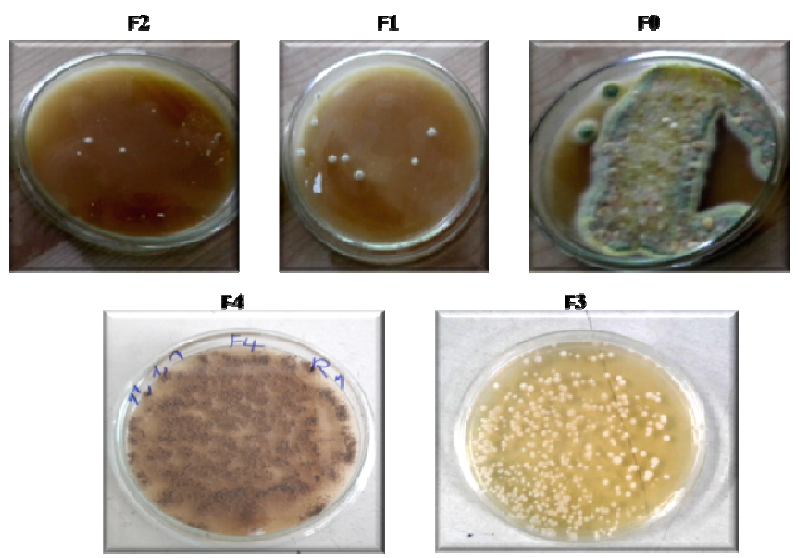

Figure 3: View of spores of Talaromyces Flavus at a Concentration of 100 Spores per Milliliter of Different

Formulations on the PDA Medium in the First three Months after Preparation

F0 (Previous Formulation), F1 (Nanocapsule 1), F2 (Nanoemulsion)

F3 (Nanocapsule 2) and F4 (Nanopowder)
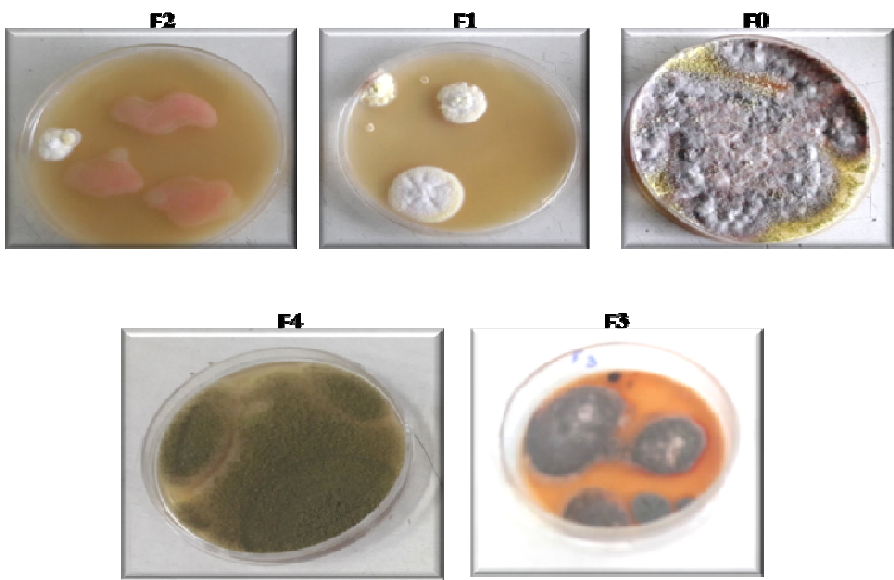

Figure 4: View of Spores of Talaromyces Flavus at 10 Concentrations In Milliliters of Different

Formulations on the PDA Medium in the Second Three Months after Preparation:

F0 (Previous Formulation), F1 (Nanocapsule 1), F2 (Nanoemulsion), F3 (Nanocapsule 2) and F4 (Nanopowder)

Table 2: Comparison of the Means Active Population Per Gram of Different Talaromyces

Flavus Formulations (Formulations Based on Nanotechnology and Rice Bran

Formulation Based on Previous Technical Knowledge) in Logarithmic Basis

\begin{tabular}{|l|c|c|l|c|}
\hline \multicolumn{1}{|c|}{ Formulation } & \multicolumn{3}{|c|}{ Mean active population/ gram } \\
\cline { 2 - 5 } & $\begin{array}{l}\text { Mean active } \\
\text { population per } \\
\text { gram at } \\
\text { logarithmic basis }\end{array}$ & $\begin{array}{c}\text { Mean active } \\
\text { population per } \\
\text { gram }\left(\times \mathbf{1 0}^{\mathbf{9}}\right)\end{array}$ & $\begin{array}{l}\text { Mean active } \\
\text { population per } \\
\text { gram at } \\
\text { logarithmic } \\
\text { basis }\end{array}$ & $\begin{array}{c}\text { Second three months } \\
\text { Mean active } \\
\text { population per } \\
\text { gram }\left(\times \mathbf{1 0}^{\mathbf{9}}\right)\end{array}$ \\
\hline $\begin{array}{l}\text { F0(Previous } \\
\text { Bioformulation) }\end{array}$ & $9.17 \mathrm{a}^{*}$ & 1.50 & $9.25 \mathrm{c}^{*}$ & 1.80 \\
\hline F1 (Nanocapsule 1) & $8.95 \mathrm{a}$ & 0.90 & $9.47 \mathrm{~b}$ & 3.00 \\
\hline F2 (Nanoemulsion) & $8.47 \mathrm{~b}$ & 0.30 & $9.30 \mathrm{bc}$ & 2.00 \\
\hline F3 (Nanocapsule 2) & $9.00 \mathrm{a}$ & 1.00 & $9.07 \mathrm{~d}$ & 1.20 \\
\hline F4 (Nanopowder) & $8.00 \mathrm{c}$ & 0.1 & $9.69 \mathrm{a}$ & 5.00 \\
\hline
\end{tabular}

* There is no statistically significant difference among the means with the same statistical letters in the $1 \%$ probability level. 
Overall, the results of this research showed that in the different T. flavus nanoformulations prepared as a capsule, emulsion and powder from the preparation date up to six months after preparing, the number of spores and the active population of the fungus was higher than $10^{8}$ per gram of formulation. According to previous research, the colony forming unit (CFU) of fungal or bacterial microorganisms has been reported in a biological product between $10^{7}$ and $10^{9}$ (Johnson and Dileone, 1999; Hammoudi et al., 2012).

\section{REFERENCES}

1. Alimi, T., Ajewole, O. C., Olubode-Awosola, O. O., and Idowu, E. O. 2006. Economic rationale of commercial organic fertilizer technology in vegetable production in Osun State of Nigeria. Journal of Applied Horticulture, 8:2: 159-164.

2. Anjali CH, Sudheer Khan S, MargulisGoshen K, Magdassi S, Mukherjee, Amitava Chandrasekaran N. 2010. Formulation of waterdispersible nanopermethrin for larvicidal applications. Ecotoxicology and Environmental Safety . 73(8): 1932-1936.

3. Ardakani, S. S., Heydari, A., Khorasani, N., and Arjmandi, R. 2010. Development of new bioformulations of Pseudomonas fluorescens and evaluation of the products against damping-off of cotton seedlings. Journal of Plant Pathology, 2: 1: 83-88.

4. Budge, S. P., and Whipps, J. M. 2001. Potential for integrated control of Sclerotinia sclerotiorum in glasshouse lettuce using Coniothyrium minituns and reduced fungicide application. Phytopathology, 91:2: 221-227.

5. Caramez, M., Damaso, T., Costaterzi, S., Farias, A. X., Pereira de Oliveira, A. C., Fraga, M. E., and Couri, S. 2012. Selection of cellulolytic fungi isolated from diverse substrates. Brazilian Archives of Biology and Technology, 55:4: 513-520.

6. Ebrahimnejad P, Dinarvand R, Jafari MR, Tabasi SAS, Atyabi F. 2011. Characterization, blood profile and biodistribution properties of surface modified PLGA nanoparticles of SN-38. International Journal of Pharmaceutics. 406(1-2): 122-127.

7. Engelelkes, C. A., Nuclo, R. L., and Fravel, D. R. 1997. Effect of carbon, Nitrogen, and C:N ratio on growth, sporulation, and biocontrol efficacy of Talaromyces flavus. Phytopathology, 87: 500-505.

8. Farhang Niya, S., Naraghi, L., Ommati, F., Pirnia, M. 2015. Evaluation of the efficacy of the biological compound affected by Talaromyces flavus in controlling tomato Fusarium wilt disease in the field conditions. International Journal of Agricultural Science and Research, 5: 2: 153-164.

9. Guan H, Chi D, Yu J, Li X. 2008. A novel photodegradable insecticide: Preparation, characterization and properties evaluation of nano-Imidacloprid. pestic biochem physiology. 92(2): 83-91.

10. Hammoudi, O., Salman, M., Abuamsha, R., Ehlers, R. 2012. Effectiveness of bacterial and fungal isolates to control phoma lingam on oilseed rape, Brassica napus. American Journal of Plant sciences, 3:1: 773-779.

11. Heydari, A., and Pessarakli M. 2010. A review on biological control of fungal plant pathogens using microbial antagonists. Journal of Biological Sciences, 10: 272-290.

12. Husen, E., Simanungkalit, R. D. M., Suraswati, R., and Irawan, I. 2007. Characterization and quality assessment of Indonesian commercial biofertilizer. Indonesian Journal of Agricultural Science, 8:1; 31-38.

13. Johnson, k. B., Dileone, J. A. 1999. Effect of antibiosis on antagonist dose-plant disease response relationships for the biological control of crown gall of tomato and cherry. Phytopathology, 89:1: 974-980.

14. Kaewchai, S., Soytong, K., and Hyde, K. D. 2009. Mycofungicides and fungal biofertilizers. Fungal Diversity, 38: 25-50.

15. Kakvan, N., Heydari, A., Zamanizadeh, H. R., and Naraghi, L. 2013. Development of new bioformulations using Trichoderma and Talaromyces fungal antagonists for biological control of sugar beet damping-off disease. Crop Protection, 53: 1: 80-84. 
16. Kah, M. and Hofmann, T. 2014. Nanopesticide research: current trends and future priorities. Environment international, 63: 224-235.

17. Kakvan, N., Hydrae, A., Zamanizadeh, H. R., Rezaee, S., and Naraghi, L. 2013. Development of new bioformulations using Trichoderma and Talaromyces fungal antagonists for biological control of sugar beet damping-off disease. Crop Protection, 53: $80-84$.

18. Khabbaz, S. E., and Abbasi, P. A. 2014. Isolation characterization and development of antagonistic bacteria for the management of seedlings damping-off and root rot disease of cucumber. Canadian Journal of Microbiology, 60: 1: 25-33.

19. Khan, N. T., and Jameel, N. 2016. Antifungal activity of silver nanoparticles produced from fungus, Penicillium fellutanum at different pH. Journal of Microbial and Biochemical Technology, 8:5: 440-443.

20. Kirthi AV, Rahuman AA, Rajakumar G, Marimuthu S, Santhoshkumar T, Jayaseelan C, et al. 2011. Acaricidal, pediculocidal and larvicidal activity of synthesized $\mathrm{ZnO}$ nanoparticles using wet chemical route against blood feeding parasites. Parasitol Res . 109(2): 461-472 .

21. Koch, E. 1999. Evaluation of commercial products for microbial control of soil-borne plant disease. Crop Protection, 18:2: $119-125$

22. Lee, S., and Lee, J. 2009. Color stabilization of low toxic antimicrobial polypropylene/poly (hexamethylene guanidine) phosphate blends by Taguchi technique. Macromolecular Research, 17: 411-416.

23. Maji, R., Dey, N., Satapathy, B., Mukherjee, B. and Mondal, S. 2014. Preparation and characterization of Tamoxifen citrate loaded nanoparticles for breast cancer therapy. International journal of nanomedicine, 9: 3107.

24. Mansoori, M., Heydari, A., Hassanzadeh, N., Rezaee, S., and Naraghi, L. 2013. Evaluation of Pseudomonas and Bacillus bacterial antagonists for biological control of cotton Verticillium wilt disease. Journal of Plant Protection Research, 53: 154156.

25. Margulis-Goshen, K. and Magdassi, S. 2013. Nanotechnology: an advanced approach to the development of potent insecticides. Advanced Technologies for Managing Insect Pests. (ed.), pp. 295-314. Springer.

26. Martín, Á., Varona, S., Navarrete, A. and Cocero, M. 2010. Encapsulation and co-precipitation processes with supercritical fluids: applications with essential oils. The Open Chemical Engineering Journal, 4:1: 31-41.

27. Mehdizadehnaraghi, R., Hydrae, A., Zamanizadeh, H. R., Rezaee, S., and Nikandam, J. 2015. Promotion of garlic growth characteristics using bioformulations developed based on antagonistic fungi. International Journal of Agriculture and Crop Sciences, 8:5: 654-658.

28. Merwel, c., Hansen, B. S., Maurice, H., and Vaughan, J. R. 1974. Mechanism of action of the mycotoxin Trichodermin, a 12,13-Epoxytrichothecene. Proceedings of the National Academy of Sciences of the united states of America, 71: 713-717.

29. Naraghi, L., Arjmandian, A., Heydari, A., Sharifi, K., and Afshari Azad, H. 2014a. A comparison between carbendazim fungicide and Talaromyces flavus in controlling Verticillium wilt of potato under field conditions. International Journal of Agricultural Science and Research, 4: 1: 89-100.

30. Naraghi, L., Heydari, A., Hesan, A., and Sharifi, K. 2014b. Evaluation of Talaromyces flavus and Trichoderma harzianum in biological control of sugar beet damping-off disease in the greenhouse and field conditions. International Journal of Agricultural Science and Research, 4: 1: 65-74.

31. Naraghi, L., Heydari, A., Rezaee, S., Razavi, M., and Afshari-Azad, H. 2010a. Biological control of greenhouse cucumber Verticillium wilt disease by Talaromyces flavus. Phytopathologia Mediterranea, 49: 321-329. 
32. Naraghi, L., Heydari, A., Rezaee, S., Razavi, M., and Jahanifar, H. 2010b. Study on antagonistic effects of Talaromyces flavus on Verticillium albo-atrum, the causal agent of potato wilt disease. Crop Protection, 29: 7: 658-662.

33. Naraghi, L., Heydari, A., Rezaee, S., Razavi, M., Jahanifar, H., and Mahmoodi Khaledi, E. 2010c. Biological control of tomato Verticillium wilt disease by Talaromyces flavus. Journal of Plant Protection Research, 50: 3: 360-365.

34. Naraghi, L., Heydari, A., Rezaee, S., and Razavi, M. 2012a. Biocontrol agent Talaromyces flavus stimulates the growth of cotton and potato. Journal of Plant Growth Regulation, 31: 471-477.

35. Naraghi, L., Heydari, A., Rezaee, S., Razavi, M., and Afshari-Azad, H. 2012b. Promtion of growth charasteristics in greenhouse cucumber and tomato by Talaromyces flavus. International Journal of Agricultural Science and Research, 2: 3: 129-141.

36. Ostertag, F., Weiss, J., McClements, D.J., 2012. Low-energy formation of ediblenanoemulsions: factors influencing droplet size produced by emulsion phaseinversion. J. Colloid Interface Sci. 388, 95-112.

37. Pascual, S., Melgarejo, P., and magan, N. 1999. Production of the fungal biocontrol agent Epicoccum nigrum by solid substrate fermentation: effect of water activity on accumulation of compatible solutes. Mycopathologia, 146: 1: 83-89.

38. Pereira, I., Ortegu, R., Barrientus, L., Moya, M., Reyes, G., and Kramm, V. 2009. Development of a biofertilizer based on filamentous nitrogen- fixing cyanobacteria for rice crops in Chile. Journal of Applied Phycology, 21: 1: 135-414.

39. Prabakaran, K., Ragavendran, C. and Natarajan, D. 2016. Mycosynthesis of silver nanoparticles from Beauveria bassiana and its larvicidal, antibacterial, and cytotoxic effect on human cervical cancer (HeLa) cells. An international journal to further the chemical sciences. 6: 44972-44986.

40. Prasad, R., Kumar, V. and Prasad, K.S. 2014. Nanotechnology in sustainable agriculture: present concerns and future aspects. African Journal of Biotechnology, 13: 6: 705-713.

41. Priyadarshini, E., Pradhan, N., Behari Sukla, L., Kumar Panda, P., and Kanta Mishra, B. 2014. Biogenic synthesis of floralshaped gold nanoparticles using a novel strain, Talaromyces flavus. Annals Microbiology, 64:3: 1055-1063.

42. Rajakumar G, Abdul Rahuman A. 2011. Larvicidal activity of synthesized silver nanoparticles using Eclipta prostrata leaf extract against filariasis and malaria vectors. Acta Tropica. 118(3): 196-203.

43. Salunkhe RB, Patil SV, Patil CD, Salunke BK. 2011. Larvicidal potential of silver nanoparticles synthesized using fungus Cochliobolus lunatus against Aedes aegypti (Linnaeus, 1762) and Anopheles stephensi Liston (Diptera; Culicidae). Parasitology Research. 109(3): 823-831.

44. Sargin, S., Gezgin, Y., Eltem, R., and Vardar, F. 2013. Micropropagule production from Trichoderma harzianum EGE-K38 using solid-state fermentation and a comparative study for drying methods. Turkish Journal of Biology, 37: 1: 1-8.

45. Schuster, A., and Schmoll, M. 2010. Biology and biotechnology of Trichoderma. Applied Microbiology and Biotechnology, 87: 3: 787-799.

46. Shahraki, M., Heydari, A., and Hasanzadeh, N. 2009. Investigation of antibiotic, siderophore, volatile metabolites production by Bacillus and pseudomonas bacteria. Iranian Journal of Biology, 22: 71-84.

47. Vasane, S. R., and Kothari, R. M. 2008. An integrated approach to primary and secondary hardening of banana Var. Grand Naine. Indian Journal of Biotechnology, 7:2: 240-245.

48. Wan-Jun Sh, Wei-Wei Sh, Sai-Yan G, Yi-Tong L, Yong-Song C, Pei Zh. 2010. Effects of nanopesticide chlorfenapyr on mice. Toxicological \& Environmental Chemistry. 92(10): 1901-1907. 
49. Zhang, Q., Hua, G. and Adang, M. J. 2015. Chitosan/DsiRNA nanoparticle targeting identifies AgCad1 cadherin in Anopheles gambiae larvae as an in vivo receptor of CryllBa toxin of Bacillus thuringiensis subsp. Jegathesan. Insect Biochemistry and Molecular Biology, 60: 33-38. 